University at Albany, State University of New York

Scholars Archive

\title{
Identidades por negociar: La presentación de la piel humana en la fotografía de René Peña.
}

Ilka Kressner

University at Albany, State University of New York, ikressner@albany.edu

Follow this and additional works at: https://scholarsarchive.library.albany.edu/cas_llc_scholar

Part of the Photography Commons, Race, Ethnicity and Post-Colonial Studies Commons, and the Visual Studies Commons

\section{Recommended Citation}

Kressner, Ilka, "Identidades por negociar: La presentación de la piel humana en la fotografía de René Peña." (2010). Languages, Literatures and Cultures Faculty Scholarship. 17.

https://scholarsarchive.library.albany.edu/cas_llc_scholar/17

This Book Chapter is brought to you for free and open access by the Languages, Literatures \& Cultures at Scholars Archive. It has been accepted for inclusion in Languages, Literatures and Cultures Faculty Scholarship by an authorized administrator of Scholars Archive. For more information, please contact scholarsarchive@albany.edu. 


\title{
IDENTIDADES POR NEGOCIAR: LA PRESENTACIÓN DE la Piel humana en la fotografía de René PENAa
}

\author{
Ilka Kressner \\ State University of New York, Albany
}

Cuba, ese sueño frustrado de utopía social, es uno de los lugares más visualizados de las Américas. Es imposible emprender un estudio de su fotografia sin la presencia fantasmal de los barbudos, marchando abrazados, a paso largo con su aura de "el mundo es nuestro", o el eterno retorno iconográfico del cliché Che de Alberto Korda, una de las imágenes más reproducidas del siglo $\mathrm{xx}$. El objetivo central de esas avalanchas iconográficas ha sido y es, por supuesto, ideológico: sirven para crear, proyectar y aseverar el lugar histórico de la nueva Cuba.' El crítico Eugenio Valdés Figueroa destaca que la primera ola de fotografía cubana pos-revolucionaria, «adoptó la estrategia de decir visualmente lo que los líderes revolucionarios ya estaban diciendo verbalmente. Imagen y palabra simplemente [...] redujeron la posibilidad de interpretaciones plurales y de ambigüedad a lo mínimo" (19). ${ }^{2}$ Ese uso redundante y restrictivo de la fotografía ha sido contestado desde los años sesenta, tanto por artistas como por críticos. Los primeros ejemplos post-revolucionarios que debaten la ilusión del realismo fotográfico son probablemente la exhibición Foto-Mentira, montada en La Habana en 1965 y el ensayo "La imagen fotográfica del subdesarrollo» de Edmundo Desnoes (1967), análisis influyente de la forografía como celada de una supuesta realidad que se revela como proyección ideológica. ${ }^{3}$

1 Las muestras excesivas también satisfacen el deseo desde afuera de asir ese sitio vedado $y$ contestado, en el caso de los Esrados Unidos de América, de vislumbrar más allá de las 90 millas que separan Key West de La Habana. Como nos recuerda Michel Foucault, no hay nada tan poderoso como producir la ficción de un deseo reprimido que la existencia de una ley prohibitoria $(1976: 35-67)$.

Todas las traducciones son mías.

Desnoes analiza las fotografias publicitarias y de prensa sobre países subdesarrollados, consumidas en países del primer mundo, en especial las estrategias de representar al otro como objeto y estereotipo exótico del observador-sujeto estadounidense o europeo. Sus comparaciones de las fotografías de Fidel Castro en la prensa estadounidense, francesa, española y soviéti- 
La conciencia del poder manipulador sigue siendo palpable en la fotografía cubana contemporánea. Las obras nacen y exponen una honda sospecha de sus propios poderes manipuladores. De diferentes maneras presentan efectos de distanciamiento y apuntan a dilatar y prorrogar las interpretaciones de los observadores, y de allí, exploran nuevas posibilidades críticas y creativas de lo visual. Esa invitación de leer las imágenes fotográficas 'con sospecha' se traduce tanto al nivel técnico como al nivel temático. A través de la manipulación de negativos, el uso del fotomontaje y la inserción de close-up's extremos, las obras revelan el potencial demagógico y retan al discurso autoritario. Para dar un ejemplo, Eduardo Aparicio, en Triunfos (1994-1995) presenta un desbarajuste de objetos diarios de la marca Triunfo excesivamente etiquetados que refutan el mismo título de la serie. Su colega Manuel Piña contrapone lo visual y lo verbal en su serie irónica Manipulaciones, verdades y otras mentiras (1994-1995): en una fotografía muestra en close-up las piernas abiertas de una mujer caminando. A distancia, entre sus piernas, se ven una barrera (¿frontera?) y un obelisco de forma fálica, seguidos por el slogan "aquí es la luz", que hace referencia a la figura de la xjinetera" o prostituta accidental para turistas. La representación deconstructiva de ciertos estereotipos y la orientación hacia un vocabulario más intimista son algunas de las técnicas más frecuentemente utilizadas para cuestionar la imagen pública ( $y$ púdica) oficial. Los dispositivos de distanciamiento advierten al observador de no suspender el mundo exterior al mirar una imagen fotográfica para no caer en la trampa ceguera de confundir el status quo con el status imago.

En las páginas siguientes, me propongo estudiar la obra fotográfica de René Peña. Quisiera analizar su obra desde el punto de vista de las presentaciones de la piel humana: a través de sus enfoques peculiares y multifacéticos en la piel, Peña logra traducir la sospecha de una percepción simplista de lo visual y, en consecuencia, plantea la noción de la identidad en términos novedosos, cambiantes, individuales, radicalmente opuestos a la visión superficial de una identidad ideologizada y colectiva.

Nacido en La Habana en 1957, Peña es hoy uno de los fotógrafos cubanos más reconocidos, con una larga lista de exposiciones en Sudamérica, los Estados Unidos y Europa. Es conocido como artista de fotografía formalista en

ca después de la Revolución son ejemplos muy reveladores de análisis semióticos de las estrategias de visualizar las inclinaciones y convicciones de las respectivas publicaciones (1967: $74-82)$. 
blanco y negro. Su tema favorito es el cuerpo humano. El desarrollo artístico de este fotógrafo espejea los cambios socioculturales e ideológicos que han tenido lugar en Cuba en los últimos veinte años. A comienzos de los noventa, durante el "Período Especial» de honda inseguridad política y crisis económica y la siguiente apertura de la isla al turismo de masas, la cámara de Peña capta los cambios sociales en las calles de La Habana y muestra encuentros inesperados y a menudo desconcertantes en su serie "Crónica de la ciudad" (1991). Luego, se desplaza de lo social a lo íntimo para retratar espacios domésticos en «Hacia adentro" (1994) y "Doctrinas de lo impropio» (1996), en donde explora estrategias de resistencias y supervivencias individuales en ese mundo vertiginosamente cambiante de la mitad de los años noventa. La nueva ola de dolarización y comercialización masiva resuena en "White Things" (2001), serie de trabajos que representan el cuerpo humano -sobre todo autorretratos del fotógrafo- en close-ups y poses artificiales, con distintos objetos blancos, como por ejemplo camisas, corpiños, pulseras, latas, paraguas, auriculares o muñecas. ${ }^{4}$

Esa última serie ha sido descrita como arte de una "provocación narcisista» (Horstmann) y le ha otorgado a Peña la reputación dudosa de ser el nuevo Robert Mapplethorpe cubano (Castro Martín 2003: 2). No estoy de acuerdo con esas interpretaciones: el argumento de una escenificación teatral a la Mapplethorpe no convence si se toma en cuenta la selección de los márgenes y las poses diversificadas, a veces embarazosas de los cuerpos, además de imágenes de modificaciones corpóreas, incluso el proceso de envejecimiento. El mero hecho de que Peña exponga cuerpos desnudos en blanco y negro no es razón suficiente para describirlo como discípulo de Mapplethorpe, especialmente si se considera la insistencia en el retrato de un solo cuerpo, dejando al lado las restricciones económicas y materiales de un fotógrafo en la Cuba de los noventa. En cuanto al reproche de sus poses narcisistas, quisiera argumentar lo contrario y proponer que el cuerpo, hoy, es el único terreno experimental y fuente de conocimiento crítico del individuo (que es, de hecho, el argumento de los artistas del proyecto Body Radical, quienes utilizan sus propios cuerpos como medios de expresión artística). ${ }^{5}$

${ }^{4}$ Esa serie es la más conocida internacionalmente del fotógrafo ya que ha sido expuesta parcial o enteramente además de en Cuba, Méxiç, Estados Unidos, España, Alemania, Suiza, Francia y en Malasia.

"Para un análisis detallado de las obras de los artistas de Body Radical véase el artículo de Saled (2001: 32-35). 
La mayoría de las críticas de la fotografía de Peña subraya el aspecto abiertamente político de su obra, en especial, la denuncia del racismo. ${ }^{6}$ Su fotografía apunta al discurso racista, basado en la «epidermización» de la inferioridad, según las concepciones de Frantz Fanon, elaboradas en Black Skin, White Masks. Según señala Elvira Rosa Casto Martín, "René Peña siempre ha usado su cuerpo como blanco de agresión al espectador. [...] Hay en ello el reclamo de la belleza negra,... [según] sus propios cánones. Negritud que manipula, se burla y se afirma, todo a un tiempo, en clichés de tradición popular" (Ibíd.: 16). Alejandro Artalejo Taquechel interpreta su obra de manera similar, aunque en términos menos categóricos y binarios:

Peña ha enfocado su trabajo (o gran parte de éste) al cuerpo masculino, pero no sólo con una connotación sexual, sino también socialmente marcado desde un punto racial que va desde la consolidación [...] de estereotipos donde el negro aparece como símbolo sexual hasta el concepto desgarrador donde podemos apreciar la fuerte lucha contra tan marcada marginalidad de género (2008: s. p.).

A través de sus presentaciones idiosincrásicas y yuxtaposiciones desconcertantes, del uso de la metáfora, de la ambigüedad y de la ironía, la obra de Peña refuta la oposición binaria entre negro y blanco y apunta a la presencia de prejuicios raciales en un país que pretende no tenerlos. Para el fotógrafo, el concepto de blancura es en primer lugar una actitud discriminatoria. En segundo lugar asocia lo blanco con un ideal mercantil impuesto a la sociedad (Posner 2003: 16). Es interesante notar que el mismo artista pone menos énfasis en la presentación de la negritud estigmatizada que sus críticos. En una mesa redonda sobre "masculinidad» que tuvo lugar en la Casa de las Américas en La Habana en Febrero de 2007, explicó: "No me es determinante la raza o el género del cuerpo. [Por eso] no me parece lógico salir a buscar otro modelo cuando yo mismo tengo un cuerpo siempre a mano. Como soy negro, es imposible que en mis fotos aparezca otra cosa" (Peña 2007). Preguntado por su predilección del cuerpo desnudo, Peña expresó que quería reducir las referencias socioculturales a lo mínimo para enfocar los rasgos colectivos de los humanos. Sin embargo, hay que tomar ese argumento con precaución, ya que el cuerpo, como nos recuerda Octavio Paz, «es siempre un

Véanse, entre otros, los estudios de Posner (2003), Valdés Figueroa (2003), Casto Martín (2003) y Mosquera (1999). 


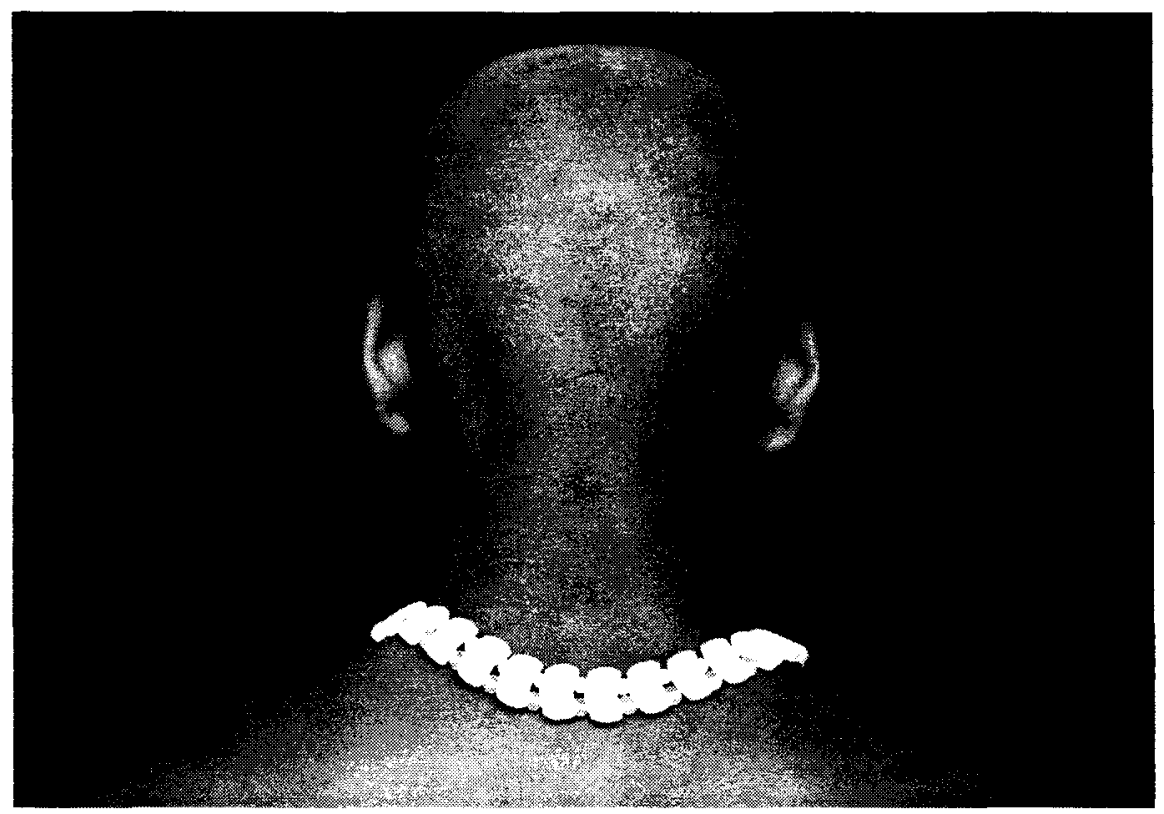

René Peña, White Things, 2001.

más allá del cuerpo» (2001: 125). Los cuerpos de las fotografías de Peña se presentan raras veces como unidades tridimensionales. Se exponen a menudo como superficie - aunque irregular-que es la piel humana. La piel es una de las metáforas artísticas más destacadas para traducir la identidad humana. Ese punto de interacción entre el interior y el mundo circundante nos comunica la forma del mundo y a la vez nos da nuestra forma en éste.

La presentación de la piel en la fotografía de Peña propone lecturas inesperadas: el artista cuestiona y en ciertas ocasiones hasta borra las distinciones entre el plano central y el fondo y entre el objeto tridimensional (el centro tradicional de la atención) y el trasfondo bidimensional. A primer vistazo, el collar de una de las fotografías de "White Things" parece ser el objetivo central de la imagen. La silueta humana casi no se distingue del trasfondo oscuro. Sin embargo, después de rastrear la superficie unos instantes más, el ojo

Esa interacción ha sido analizada recientemente por Didier Anzieu, quien, en su Skin Ego propone que «el ego es la proyección de la psique sobre la superficie del cuerpo" / «the ego is the projection of the psyche on the surface of the body" (1989: 40). 


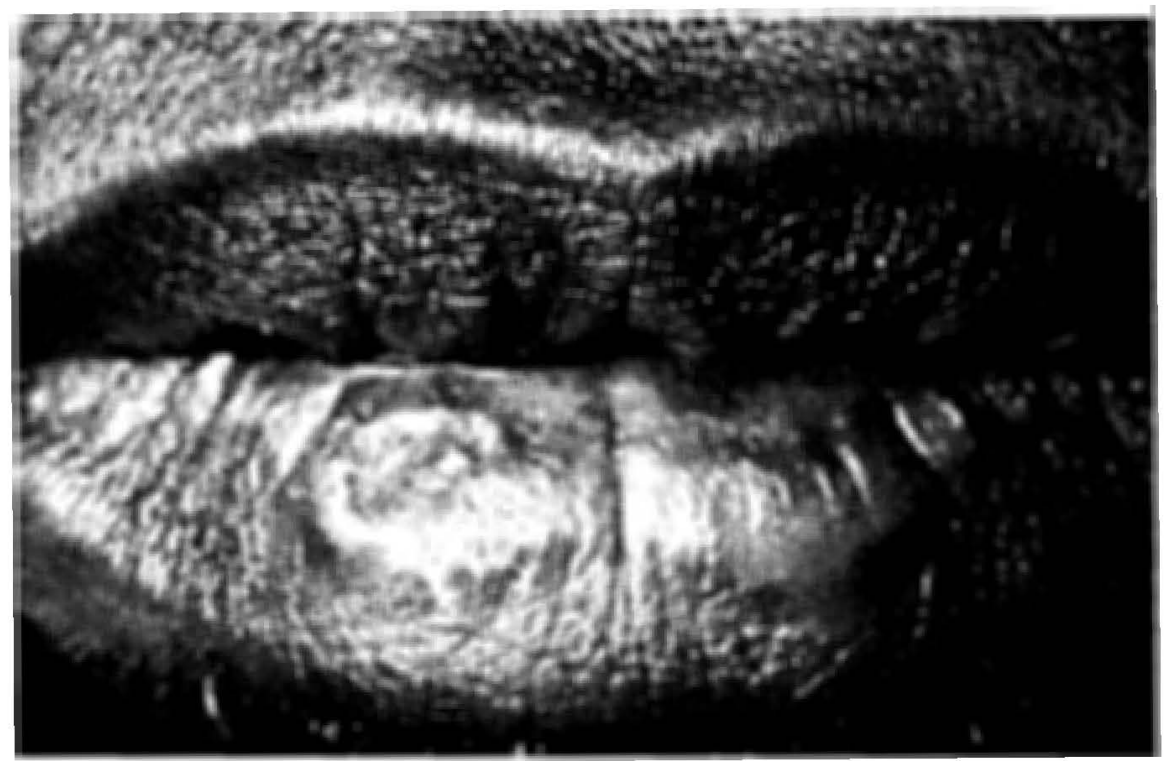

René Peña, Man Made Materials, 1997.

del observador se queda intrigado más por la figura sinuosa del cuerpo que por las líneas brillantes del collar (¿o hasta de la cadena?) alrededor del cuello de la persona retratada. La "cosa blanca» luminosa, introducida por el título de la colección, ha sido mero atractivo superficial para explorar el cuerpo humano con su silueta vaga, sus concavidades y curvas. En una lectura desacelerada y a la vez más activa y dinámica, la forma reducida y desigual de la epidermis mueve al centro de la atención para últimamente eclipsar el artículo en blanco. Esa lección de la mercancía escalonada al segundo rango, del objeto visualmente atractivo, deslucido por su supuesto trasfondo que se revela como cuerpo de acción, se puede interpretar como ejemplo de una estrategia alternativa, de leer la cultura presente, de lentamente descifrar los elementos escondidos de la imagen (la piel del ser humano) y de desmantelar el fetiche de lo inanimado. En un nivel meta-pictórico, la fotografía también reta, según indica Mieke Bal, "la convención visual de ver una imagen como ente unificado" (1991: 212), además de "la concepción de que... el arte visual puede ser visto en un solo instante» (2001: 245). Peña invita a sus observadores a ser sospechosos de los peligros de representación y alienta a efectuar una lectura activa, retardada para aumentar la percepción del supuesto trasfondo que se revela el objetivo mayor. 
Las series "Memorias de la carne" (1997), "Man Made Materials" (1997) y "White Things» (2001) muestran la piel humana como sitio marcado por experiencias individuales, como metáfora principal de identidad, presentada como entidad en proceso perpetuo. Este órgano, al límite extremo del cuerpo humano, es tanto barrera como medio de intercambio. ${ }^{8}$ Simultáneamente protege el interior e interacciona con el mundo circundante. En la obra fotográfica de Peña, es un recuerdo vivo de tiempos pasados: exhibe cortaduras, cicatrices, tatuajes, poros, arrugas y líneas de vidas sinuosas. También se presenta como medio de un intercambio presente con el exterior (por ejemplo las gotas de sudor de varias obras) o incluso como interfaz de prefiguraciones futuras. La insistencia de Peña en las irregularidades, las formas amorfas y las inscripciones en la piel son significativas. El músculo que abulta la membrana, los poros y las cicatrices expuestas narran historias mínimas de resistencias íntimas, de adaptaciones, reflejos, intercambios y de inscripciones de un afuera. El enfoque en la piel se vuelve apelación a la necesidad de una interpretación individual en materia de un presente determinado para desmentir las iconografías repetidas y sentencias preestablecidas.

La piel insiste, recuerda y revela. Según Jay Prosser, «en su color, textura, marcas y manchas acumuladas, rememora algo de nuestra clase, de nuestras actividades laborales y aficiones, hasta nuestra relación más íntima hacia nuestros cuerpos" (2001: 52). Pero sería erróneo asumir que la piel representada constituya una memoria históricamente correcta; primero, porque se altera constantemente, y segundo porque resiste toda representación entera desde un punto de vista central, debido a su extensión y cobertura de todas las exterioridades del cuerpo humano.' En sus retratos de la piel humana,

" Para Jacques Derrida, la pie humana es primero una "texcura intermediaria" / "rissu intermédiaire» (14). El filósofo subraya su característica de extensión antes de tener una significación. En un argumento similar al de Anzieu, compara la piel con la psyche mitológica, descrita por Freud, en donde la mujer dormida, tendida en su lecho, es observada por el Dios Amor. La psiquis/piel es una «extensión espacial antes de ser espacio [...] abre una abertura, un intervalo» / «toute étendue est espacement avant d'être un espace, [...] ouvr[e] une ouverture, un intervaUle» (27). De modo similar al acercamiento teórico-fenomenológico de Derrida, la piel de las obras visuales de Peña se caracteriza por ser extensión, abertura y por eso potencial.

9 En las artes visuales, como ha sido estudiado extensamente, la superficie de un cuerpo tridimensional no se puede presentar enteramente. Hasta los cubistas más atrevidos eran forzados a mostrar fragmentos, excractos y recortes de ángulos diferentes. 
Peña privilegia el detalle a la unidad inconmensurable, irrepresentable o simplemente inexistente. Esa resistencia a la representabilidad total, sin embargo, no merma la veracidad del discurso epidérmico. La piel humana marca el tiempo, pero lo hace, como nota Stephen Connor, "en parte por extinción" (2001: 36). Es un sitio de memorias, incluso de memorias ficticias y fabricadas posteriormente en un presente (Prosser 2001: 67). Esa peculiaridad parcialmente fantasmal de la piel la revela como lienzo de recuerdos y proyecciones, superposiciones, alteraciones y recreaciones -como ejemplo del mismo acto creativo de presentar la identidad en proceso continuo, como fotografia por tomar.

Quisiera concluir con una observación de índole meta-fotográfica: en la obra de Peña, la piel no es una superficie lisa de gradaciones tenues entre negro y blanco, sino una capa de reflejos y refracciones nítidas entre luz y oscuridad. Todas sus fotografías tienen un brillo intenso que acentúa el contraste de la superficie y que perpetúa el juego de reflejos de luz fuera del margen, en el acá y ahora de los observadores. Mientras que la mayoría de la fotografía de modas muestra la piel como capa de terciopelo liso con un resplandor regular, la piel fotografiada de Peña absorbe (es casi enteramente negra) y espejea (refleja la luz). De esa manera, defrauda todas las expectativas de parte de un público ávido de sensaciones subcutáneas. En una fotografía sin título de "White Things», el enfoque en la boca cerrada, ese órgano prototípico de comunicación, acentúa esa resistencia de comunicar. La luz, medio de revelación visual, muestra el objeto de la foto, pero a la vez, lo disemina (en el sentido que le otorga Derrida); viene desde y apunta hacia un afuera de la mera superficie. Por eso, la misma materialidad de la luz imposibilita todo intento de inscribir un discurso fijo, monolítico de orígenes sobre la superficie del cuerpo humano. Una vez más, Peña visualiza ex negativo el potencial del arte de comunicar, de idear y abrir espacios nuevos de intercambio entre el fotógrafo, la superficie de la fotografía y la retina de los observadores. Las superficies múltiples se comunican. O, como lo describe Roland Barthes, "de un cuerpo real, que ha sido presente, proceden radiaciones que últimamente me tocan a mí, quien estoy acá... La luz, a pesar de ser impalpable, es acá [...] una piel que voy compartiendo con todos quienes han sido fotografiados" (1981: 80-81; énfasis de Barthes). A través de la presentación de la piel humana con toda su reflectividad, maleabilidad, fragmentación e interactividad, las fotografías de Peña proponen una meditación sobre la identidad como conjunto de texturas múltiples y 
cambiantes e invitan a los observadores a idear terrenos más allá de las superficies presentes.

\section{BiBLIOGRAFÍA}

Anzieu, Didier (1989): Skin Ego. New Haven: Yale University Press.

ARTALejo TAQUechel, Alejandro (2008): "El desnudo en la fotografía cubana contemporánea. Su precedente. Cuatro perspectivas. Una intención", en Arte América Dossier, 27 de enero, en <http://www.arteamerica.cu/7/dossier/taquechel.htm>. BAL, Mieke (1991): Reading "Rembrandt». Beyond the Word-Image Opposition. New York: Cambridge University Press.

- (2001): Looking in: The Art of Viewing. Amsterdam: G\&B Arts Imprint.

CONNOR, Stephen (2001): «Mortification», en Thinking Through the Skin, Sara Ahmed y Jackie Stacey (eds.). London: Routledge, pp. 36-51.

BARTHES, Roland (1981): Camera Lucida. New York: Hill and Wang.

Castro Martin, Elvira Rosa (2003): “El lenguaje misterioso de los cuerpos», en

Pulsiones. Fotografia cubana contemporánea, Elvira Rosa Castro Martín y Sandra Sosa Fernández (eds.). Bogotá: Editorial Linotipia, pp. 2-5.

Cuba. Los mapas del deseo. Landkarten der Sehnsucht. Maps of Desire (1999), catálogo de Exposición. Wien: Kunsthalle Wien Verlag, 1999.

Derrida, Jacques (2000): Le toucher. Jean-Luc Nancy. Paris: Galilée.

Desnoes, Edmundo (1967): Punto de vista. La Habana: Instituto del Libro.

FANON, Frantz (1967): Black Skin, White Masks, C. L. Markmann (trad.). New York: GrovePress.

Ғочсалт, Michel (1976): Histoire de la sexualité I. La volonté de savoir. Paris: Gallimard.

Horstmann, Fred (2008): Galeria Arte Cubano, 28 de enero, en <http://www. galeriaartecubano.com>.

Mosquera, Gerardo (1999): "The Infinite Island: Introduction to New Cuban Arr", en Contemporary Art from Cuba: Irony and Survival on the Utopian Island I Arte Contemporáneo de Cuba: Ironia y sobrevivencia en la isla utópica. Catálogo de exposición, Arizona State University Art Museum. New York: Delano Greenidge Editions, pp. 23-29.

P.z., Octavio (2001): El mono gramático. Barcelona: Seix Barral.

PENA, René (2007): «Masculinidad", en Casa de las Américas, p. 21.

Posner, Helain (2003): "Utopia. Post-Utopia», en Utopia. Post-Utopia. Conceptual Photography and Video from Cuba, Helaine Posner y Eugenio Valdés Figueroa (eds.). New Paltz: Samuel Dorsky Museum of Art (SUNY), pp. 13-17. 
Prosser, Jay (2001): «Skin memories», en Thinking Through the Skin, Sara Ahmed $y$ Jackie Stacey (eds.). London: Routledge, pp. 52-68.

SAleCL, Renata (2001): "Cut in the Body-From Clitodectomy to Body Art", en Thinking Through the Skin, Sara Ahmed y Jackie Stacey (eds.). London: Routledge, pp. 21-35.

VAl.dés Figueroa, Eugenio (2003): "The Other Face of Cuban Photography", en Utopia. Post-Utopia. Conceptual Photography and Video from Cuba, Helaine Posner y Eugenio Valdés Figueroa (eds.). New Paltz: Samuel Dorsky Museum of Art (SUNY), pp. 19-25.

Páginas de la Red con fotografias de René Peña:

$<w w w . a r t n e t . c o m / a r t i s t / 77497 /$ rene-pena.html .

$<w w w . c u b a n g a l l e r y . n e t / R e n e . P e n a>$.

<http://www.alonsoart.com/artist_view.php?id_artist=13>. 